\title{
LOW LEVEL CLOUDS ANALYSIS RELATING TO SYNOPTIC WEATHER TYPES AT BRATISLAVA AIRPORT
}

Low level clouds are one of the most important meteorological phenomena, which can significantly influence every flight phase. In general, clouds are visible indicators of physical processes realized in the atmosphere. They provide information about winds, stability, moisture content and travelling weather systems. Knowledge of cloud base is very important, particularly to a pilot on the descent to an airport flying through a cloud. Cloud base is given as the height of the base of the cloud above a particular level (usually ground level). For aerodrome reports and forecasts the base is the height above the official aerodrome level. For international airports, reports should refer to the approach area; for airports equipped with ILS reference should be to the site of the Middle Marker beacon.

This paper deals with analysis of diurnal and annual variations of low level clouds at the Slovak international airport in Bratislava. The results are applicable in aviation weather forecasting and characterizing of dynamic climate of the region.

Keywords: Low-level clouds, diurnal variation, annual variation, typical synoptic situation, Bratislava airport.

\section{Introduction}

Low level clouds are especially stratiform clouds (Stratus and Stratocumulus) in lower troposphere with base height maximally $2 \mathrm{~km}$ above ground level. Low level clouds are potentially hazardous to flight operation, but it is quite difficult to define their impacts on operation since they will depend on aircraft type, pilot skills and experience and the navigation aids available en route or at the departure/destination/alternate airport [1].

Low level clouds can extend in horizontal distance of hundreds or thousands kilometers and vertically up to the height of $1-2 \mathrm{~km}$. They can be observed in the area of warm and occluded front in central part and in a warm sector of a low pressure area (cyclone). They are also formed at the edges of anticyclone and in the case of high air mass humidity they can even originate in central part of anticyclone.

Low level clouds are usually formed by advection of warm and humid airflow over relatively colder surface. Warm advection is a typical process in warm sectors of cyclones and at the edges of anticyclones with variable duration. In the anticyclones the low level clouds are formed by radiative cooling in subsidence inversion regions below which the clouds are extended. The formation of low level clouds is also influenced by the character of an air mass or front, of which the passage is expected in the particular region, and also by the development of pressure field, to which the air mass or front is connected. The creation of low level clouds generally depends on synoptic conditions and their changes are caused by the presence of a certain weather type [2].

\section{Data and methods}

For statistical processing of daily observations from Bratislava airport, the ten-year-period 2002 - 2011 was considered. As the source of observations, the regular aeronautical meteorological reports (METARs) were used and the hourly terms were taken into account.

The dynamic-climatological weather analysis is based on application of synoptic weather types classification. Each of these types has its characteristic pressure field with defined position of central cyclones and anticyclones, location of frontal zone and probable movement of atmospheric fronts [3]. In this paper the SHMI (Slovak Hydrometeorological Institute) weather types classification is applied. This classification is processed for Central Europe region and determines 28 weather types (Table 1). Using the dynamic - climatological method, it is possible to find physical explanations of the existence of low level clouds in dependence on the occurrence of pressure patterns, air masses an airflow direction in the analyzed region during the presence of typical synoptic situation [4].

\footnotetext{
* Sandra Krollova

Department of Air Transport, Faculty of Operation and Economics of Transport and Communications, University of Zilina, Slovakia,

E-mail: krollova@fpedas.uniza.sk
} 
Synoptic weather types determined

for the Central Europe area

Table 1

\begin{tabular}{ll}
\hline \multicolumn{2}{l}{ Anticyclonic weather types } \\
Wa & Western anticyclonic situation \\
Wal & Western summer anticyclonic situation \\
$\mathrm{NWa}$ & North-western anticyclonic situation \\
$\mathrm{NEa}$ & North-eastern anticyclonic situation \\
$\mathrm{Ea}$ & Eastern anticyclonic situation \\
$\mathrm{Sea}$ & South-eastern anticyclonic situation \\
$\mathrm{Sa}$ & Southern anticyclonic situation \\
$\mathrm{SWa}$ & South-western anticyclonic situation \\
A & Anticyclone over Central Europe \\
Ap1 - 4 & $\begin{array}{l}\text { Anticyclone over Central Europe moving in different } \\
\text { trajectories }\end{array}$ \\
\hline
\end{tabular}

Cyclonic weather types

$\begin{array}{ll}\text { Wc } & \text { Western cyclonic situation } \\ \text { Wcs } & \text { Western cyclonic situation with southern trajectory } \\ \mathrm{NWc} & \text { North-western cyclonic situation } \\ \mathrm{Nc} & \text { Northern cyclonic situation } \\ \mathrm{NEc} & \text { North-eastern cyclonic situation } \\ \mathrm{Ec} & \text { Eastern cyclonic situation } \\ \mathrm{Sec} & \text { South-eastern cyclonic situation } \\ \mathrm{SWc1} & \begin{array}{l}\text { South-western cyclonic situation without distinct frontal } \\ \text { systems }\end{array} \\ \mathrm{SWc2,3} & \begin{array}{l}\text { South-western cyclonic situations with strong circulation } \\ \text { and well-developed frontal systems, }\end{array} \\ \mathrm{B} & \text { Trough of low pressure over Central Europe } \\ \mathrm{Bp} & \text { Trough of low pressure moving across Central Europe } \\ \mathrm{Vfz} & \text { Frontal zone entry } \\ \mathrm{C} & \text { Cyclone over Central Europe } \\ \mathrm{Cv} & \text { Upper cyclone }\end{array}$

In the low level clouds analysis at Bratislava airport I used the definition introduced in Annex 3 - Meteorological Service for International Air Navigation [5], according to which the significant low level cloudiness is the lowest cloud layer in amount of broken or overcast with the base height less than $1000 \mathrm{ft}$ above ground level. In terms of preparation of aviation meteorological forecasts (TAF, TREND) and special aviation meteorological reports (SPECI) the cloud base height is considered and only the data, which reach and exceed the values $100,200,500$ or 1000 $\mathrm{ft}$ in the case of prevailing IFR flights at the airport, were taken into account. Considering this requirement the cloud base values are divided into four equi-long intervals $(0-200 \mathrm{ft}, 300-500 \mathrm{ft}$, $600-800 \mathrm{ft}, 900-1100 \mathrm{ft}$ ) and their cumulative frequencies are calculated.

\section{Statistical analysis of low-level clouds at Bratislava airport}

Diurnal and annual variations of low level clouds were processed only for basic weather types. The results are depicted in 3-D isopleth-graphs and demonstrated in Figs. 1 and 2. The values of isolines are displayed in \% and derived from absolute frequencies of low level clouds with base height $\leq 1100 \mathrm{ft}$.

At Bratislava airport the low level clouds with base height $\leq 1100 \mathrm{ft}$ occurred in year average of 744 hours. The mutual percentage ratio of anticyclonic and cyclonic weather types is 58:42. This fact means that at Bratislava airport the prevailing low level clouds are of subinversion layered clouds that are typical for anticyclonic circulation. In cyclonic types the characteristic feature is the complete frequency increase in night-time and morning hours in warm half-year which is most likely caused by the radiation cooling after the front passage. The rare daytime occurrence of low level clouds is a result of direct front passage. The diurnal and annual variations for both basic weather types are depicted in Figs. 1 and 2. In the case of several weather types the highest multiplicities of low level clouds with base height less than $1100 \mathrm{ft}$ are recorded in types: SWa, SEa, B, Bp, SEc and SWc3.

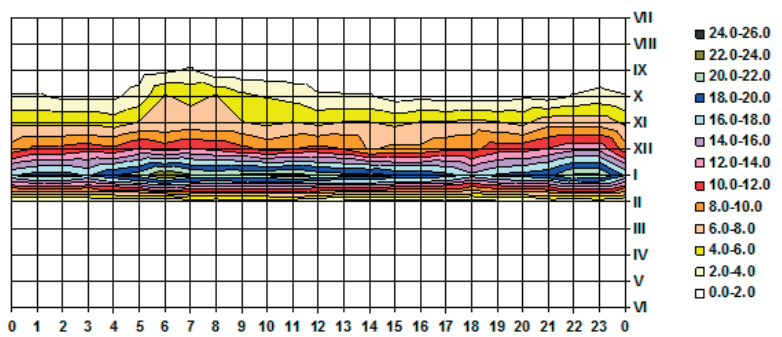

Fig. 1 Diurnal and annual variations [\%] of low level clouds with base height $\leq 1100 \mathrm{ft}$ in anticyclonic weather types at Bratislava airport (x-axis in hours, $y$-axis in months)
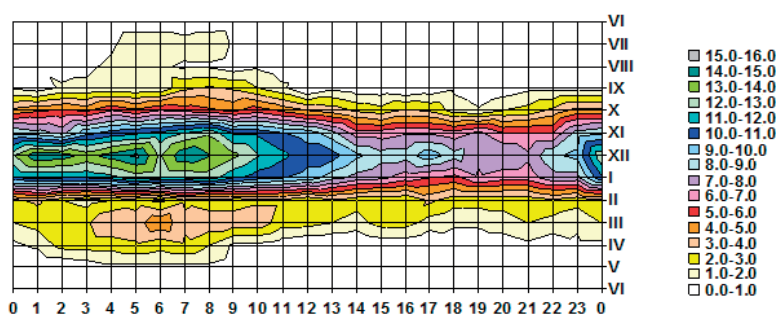

Fig. 2 Diurnal and annual variations [\%] of low level clouds with base height $\leq 1100 \mathrm{ft}$ in cyclonic weather types at Bratislava airport (x-axis in hours, $y$-axis in months)

The average frequency of low level clouds with base height less than $800 \mathrm{ft}$ reaches 622 hours in the year. In anticyclonic types the distinct frequency increasing from November is noticeable, with maximum in January and typical steep decrease in January. Cyclonic types show the similar annual variation. In the case of 
diurnal variation the anticyclonic types achieve double maximum in the early morning hours, the frequency increase in the midnight hours was recorded in types with south-western and south-eastern airflow. In cyclonic types there is a gradual frequency increase from the midnight hours with the absolute maximum at 05.00. The highest frequencies of low level clouds with base height less than $800 \mathrm{ft}$ are shown in following weather types: A, SWa, B, Bp and SEc.

At Bratislava airport the low level clouds with base height $\leq 500 \mathrm{ft}$ occurred in year average of 372 hours. In anticyclonic types the daylong occurrence of these clouds is recorded from October to February. In the case of diurnal variation the primary maximum is achieved in the morning hours $(04.00-09.00)$ with maximum values in January, the secondary one relates to the midnight hours. In cyclonic types they appear also in warm half-year, the occurrence in the morning hours proves their frontal origin. In spring and summer months the low level clouds with base height less than $500 \mathrm{ft}$ are created after the sunrise in cyclonic types; in anticyclonic ones they are not observed. In diurnal variation the most frequent occurrence of these low level clouds relates to 04.00 and 07.00 with maximum values in December. Considering the weather types the greatest producers of low level clouds with base height $\leq 500 \mathrm{ft}$ are A, SEa, SWa, Bp, Wcs, SEc, SWc2 and Vfz.

The average frequency of low level clouds with base height less than $200 \mathrm{ft}$ reaches 283 hours in the year. The highest frequencies are shown in winter months with maximum in January when the complete intensification of anticyclonic weather types realizes over the European interior. In this period the most multiple types are A, Wa and types with eastern airflow component. The first two types transport air mass with sufficient humidity. As a result of lower insolation, the air will cool from the surface, which results in stabilization of the air mass and in formation of low level layered clouds. In the case of eastern situations the continental arctic airflow will keep its distinct stability, which leads to formation of subinversion layered clouds. At the edges of anticyclones the low level clouds are predominantly caused by the advection of warm air. In summer season the anticyclonic types do not create conditions for low level clouds formation. In diurnal variation the highest frequencies are shown in time around the sunrise with maximum in January. In winter the low level clouds with base $\leq 200 \mathrm{ft}$ are also observed in daytime hours, which focuses on their advection character. The repeated increasing of low level clouds frequencies is distinct after the sunset when in autumn and winter months the temperature decrease and following condensation can cause the lowering of cloud base height below $200 \mathrm{ft}$. In cyclonic weather types the highest frequencies are achieved at the end of the year, but in general, the selected low level clouds are observed in all months. In warm half-year the limited occurrence of low level clouds relates to the early morning hours. That confirms their radiation origin of formation. In diurnal variation the most marked depletion of low level clouds base is shown in the early morning hours with maximum in December. The minimum or zero values are typical for day-time and night-time hours in spring
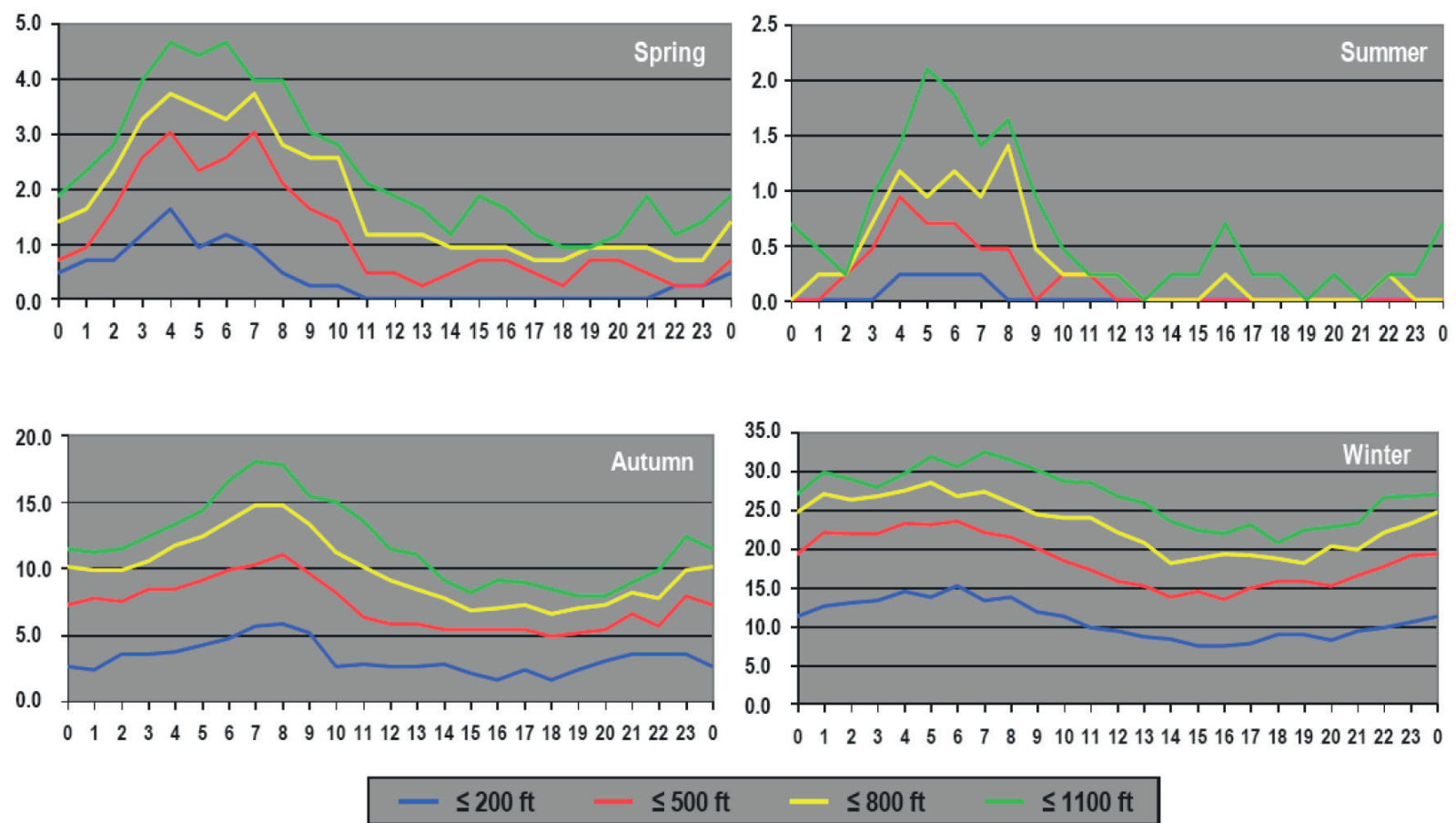

Fig. 3 Seasonal diurnal variation of low level clouds with different base height at Bratislava airport ( $x$-axis in hours, $y$-axis in \%) 
and summer months. The low level clouds are observed mainly around the sunrise time as a consequence of radiation cooling of surface air layers. The highest frequencies of low level clouds with base height $\leq 200 \mathrm{ft}$ were recorded in following weather types: A, Ea, SEa, SWa, Bp, SEc, Wc and Wcs.

In terms of effectiveness and optimal seasonal exploitation of an airport there is a possibility to apply information about seasonal occurrence of low level clouds with a certain base height. These results, relating to Bratislava airport, are depicted in Fig. 3. At first sight we can notice striking similarity between the diurnal variation in spring and summer and the diurnal variation in autumn and winter. In spring and summer months the probability curves are of approximately the same shape with difference of their steepness in the early morning hours. In autumn and winter the probability curves show the distinct maximum in the late night and early morning hours $(04.00-07.00)$. In diurnal variation the most frequent occurrence of low level clouds is observed in the early morning, two or three hours after the sunrise. Exception can be seen in the winter, when low level clouds are present during the whole night and morning hours. The characteristic depletion of low level clouds frequencies in the morning hours is depicted in a steep slope of the curve in warm half-year and in a slow course in cold months.

The seasonal occurrence of low level clouds in dependence on surface wind direction is shown in Fig. 4. The results demonstrate the significant influence of the main range of Male Karpaty on the low level clouds occurrence at Bratislava airport. In this region the secondary maximum of wind direction relates to $\mathrm{NE}$ and $\mathrm{E}$ wind, which arises as a consequence of SE wind backing on the windward side. Of course, this is influenced by presence of the weather type throughout the year. The prevailing NW wind achieves its maximum in summer; SE wind is the most frequent in autumn [6]. In terms of air mass transport between Europe and the Atlantic Ocean the maximum frequencies of NE and $\mathrm{E}$ wind are typical for the cold months and the minimum is reached in summer.

In spring low-level clouds are associated with increasing amount of cyclonic and anticyclonic weather types with airflow
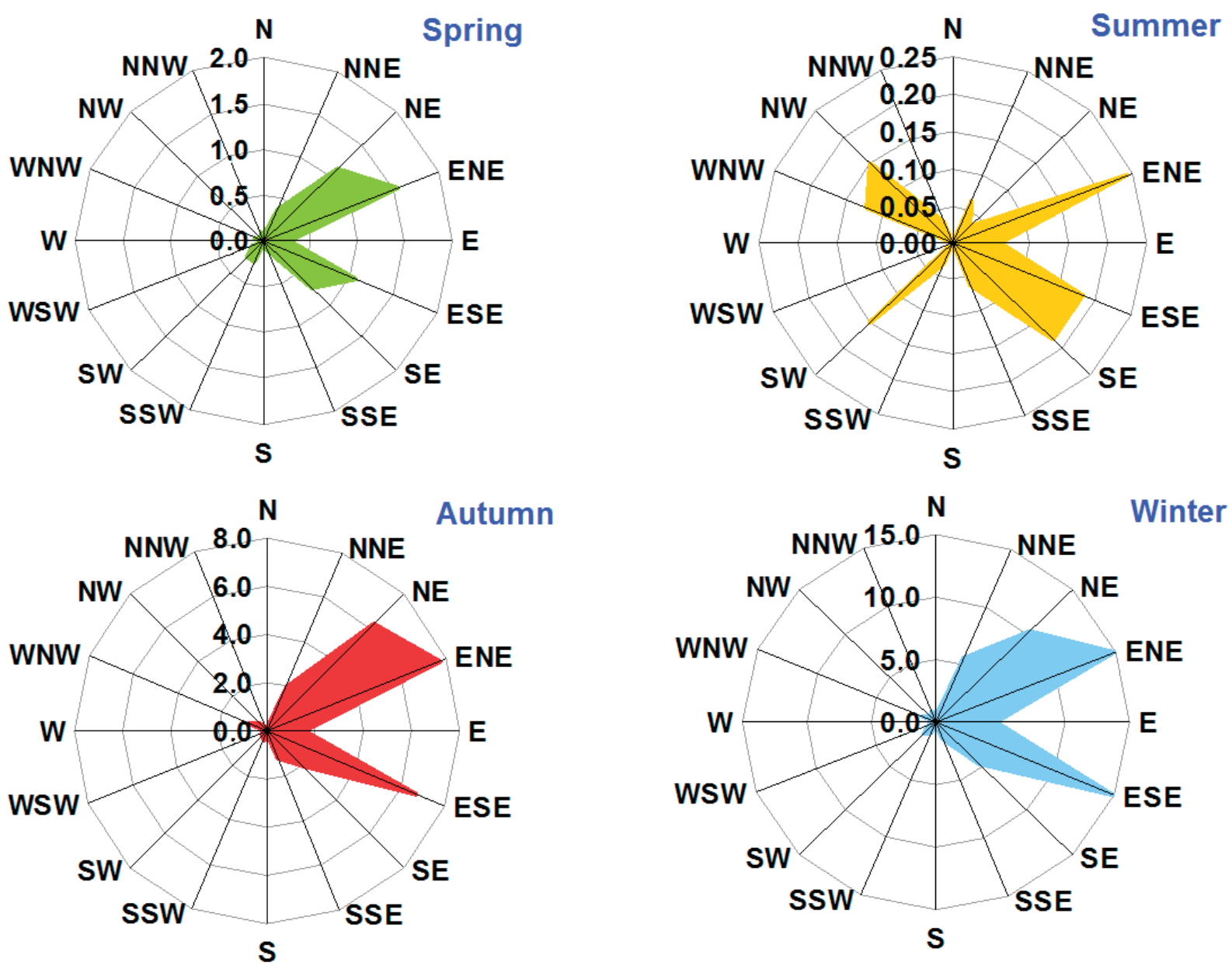

Fig. 4 Annual variation [\%] of low level clouds with base $\leq 1100 \mathrm{ft}$ depending on surface wind direction at Bratislava airport 
in the $\mathrm{N}-\mathrm{E}$ sector. This is caused by meridional circulation, which is distinct in this season. More frequent occurrence is also observed in the case of troughs of low pressure, which transport low level frontal clouds from SW. In summer the zonal circulation prevails and reaches its secondary maximum in year. The low level clouds are mostly present in E airflow. However, the large frequencies belong to the cyclonic types with the fronts moving from SW and to the ones with SE airflow. In autumn the maritime airflow decreases and weather types with continental airflow appear. The highest frequencies are typical for anticyclonic weather types and troughs of low pressure with prevailing SW and SE airflow. At the beginning of winter the zonal circulation occurs with typical increasing frequencies of the eastern and western cyclonic weather types [7].

\section{Conclusion}

When cloudbase falls below acceptable values, the pilot can encounter situation where there will not be sufficient time to take action leading to obstacle avoidance. Pilots who are not qualified to use instruments may become disorientated when they are confronted with low cloud. Therefore, the low-level clouds are one of the weather phenomena hazardous to flight operation. Low-level clouds are usually stratiform clouds - Stratus and Stratocumulus. Stratus forms in sheets or layers and occurs when relatively large areas of moist air rise gently in a stable atmosphere. It varies in thickness from a semi-transparent sheet of a few feet to a deck of around 1500 feet. When it forms close to the ground, stratus can mask the surrounding terrain, particularly in mountainous areas. Stratocumulus usually has lumpy appearance that indicates convection within the cloud. But the most significant hazard associated with low-level stratiform cloud is low visibility related to low-lying cloud base.

The occurrences of low level clouds is conditioned by several factors, e.g. time of the sunrise and sunset, elevation angle of the Sun, existence of snow cover, radiation cooling in nighttime hours, orographic conditions and characteristic of global atmospheric circulation in a specified region and in particular season. Using the calculation of diurnal and annual variations and by the applying of the dynamic - climatological method it is possible to achieve a certain model of occurrence of low-level clouds at a particular airport during the presence of individual weather types. The results are widely applicable in aviation weather forecasting. Using the data measured and observed at Bratislava airport, the results of research are directly applicable for the airport operations providing valuable prognostic information for air traffic services and ground services.

\section{References}

[1] World Meteorological Organization: WMO/TD - No. 1390 Aviation Hazards. Education and Training Programme ETR-20. Secretariat of the World Meteorological Organization. Geneva, Switzerland, 2007.

[2] ZVEREV, A. S.: Synoptic Meteorology, Bratislava, ALFA: Praha, SNTL, 1986.

[3] Kolektiv synoptickej a leteckej sluzby HMU: Catalogue of Typical Weather Situations over CSSR, Praha: MIR, 1968.

[4] BALLON, L., FORGAC, P., MOLNAR F.: Weather During the Typical Synoptic Situations over CSSR, Praha: Hydrometeorologicky ustav, 1964.

[5] Annex 3 - Meteorological Service for International Air Navigation, Part 4 - Meteorological Observing and Reporting, Publikacia Leteckej informacnej sluzby SR, Ministerstvo dopravy, post a telekomunikacii SR, druhe vydanie, 2001.

[6] Slovenska akademia vied: Climate and Bioclimate of Bratislava, Bratislava, VEDA, 1979.

[7] KROLLOVA, S.: Diurnal and Annual Variation of Low Level Clouds at Bratislava Airport (in Slovak), Intern. Conference at project AIRTN: Increasing safety and quality in civil military air transport, Zilina : Zilinská univerzita, 2011 - ISBN 978-80-554-0364-9, pp. 66-75. 